\title{
Influence of the HFIW welded joint in the fatigue resistance of an API 5CT N80 type Q steel tube used in offshore oil and gas exploration
}

\author{
Bruno Antonio Sorrija*, Marcelino P. Nascimento \\ São Paulo State University (UNESP), School of Engineering, Campus Guaratinguetá (FEG), Department of Materials and Technology (DMT), 333, \\ Ariberto Pereira da Cunha avenue, 12516-410 Guaratinguetá City, São Paulo State, Brazil
}

\begin{abstract}
A B S T R A C T
Steel pipes used in the oil and gas industry are often subjected to dynamic loading. Therefore, to mitigate fatigue cracks nucleation and growth, these steel pipes should be as flawless as possible. HFIW (High Frequency Induction Welding) process is widely used by industry in the manufacturing of steel tubes. These tubes (like the one used in this research), after being welded, are often subject to heat treatments (to improve their mechanical properties and homogenize their microstructure) and to some grinding to remove excess material from the welded joint. However, even after these processes, a discontinuity will still be present. The aim of this paper is investigate how this weld line may assume the role of a notch (stress riser) reducing the fatigue resistance of casing and tubing quenched/tempered steel pipes. The study of the fatigue resistance has been done through the analysis of results obtained from " $\mathrm{S}_{\mathrm{a}} \times \mathrm{N}$ " curves, linear regressions and estimation of a fatigue stress concentrator $\mathrm{K}_{\mathrm{f}^{\prime} \text {-notch }}$. This $\mathrm{K}_{\mathrm{f}^{\prime} \text {-notch }}$ differs from the commonly used $\mathrm{K}_{\mathrm{f}}$, and is presented in the form of an equation $\mathrm{K}_{\mathrm{f}^{\prime} \text {-notch }}=\eta \cdot \mathrm{S}_{\mathrm{a}}{ }^{\gamma}$. In the fatigue tests, non-standardized specimens, taken directly from an API 5CT N80 type Q steel tube, have been used, part of them aligned with the longitudinal weld line and the others aligned with a position situated $90^{\circ}$ from it. To complement the fatigue results, tensile tests have been carried on, as well metallographic analysis and a qualitative analysis of the welded joint geometry. The results obtained indicate that while the tube exhibit good mechanical and metallurgical homogeneity it exhibits lack of circularity (or roundness) in the adjacencies of the welded joint. In addition, from the fatigue results obtained, it is clear that the welded joint act as a stress riser, reducing the fatigue resistance of the steel pipe, with values of $\mathrm{K}_{\mathrm{f}^{\prime} \text {-notch }}$ that can be higher than 2.0 .
\end{abstract}

\section{Introduction}

Steel pipes used in the oil and gas industry are often subjected to cyclic stresses (and thus to fatigue damage) during their transportation as well during their service life. Cyclic stresses during transportation are induced by fluctuating inertial and gravitational forces [1,2] and can lead to fatigue crack nucleation, growth and, eventually, to the fracture of the steel pipe. Concerning offshore pipes (like the ones studied in this paper), service life fatigue damage mechanisms can be related to stresses induced by cyclic loading due VIVs (Vortex Induced Vibration) [3,4], oil and gas flow induced vibrations, temperature and pressure

\footnotetext{
* Corresponding author.

E-mail address: sorrija.bruno@usp.br (B.A. Sorrija).
} 

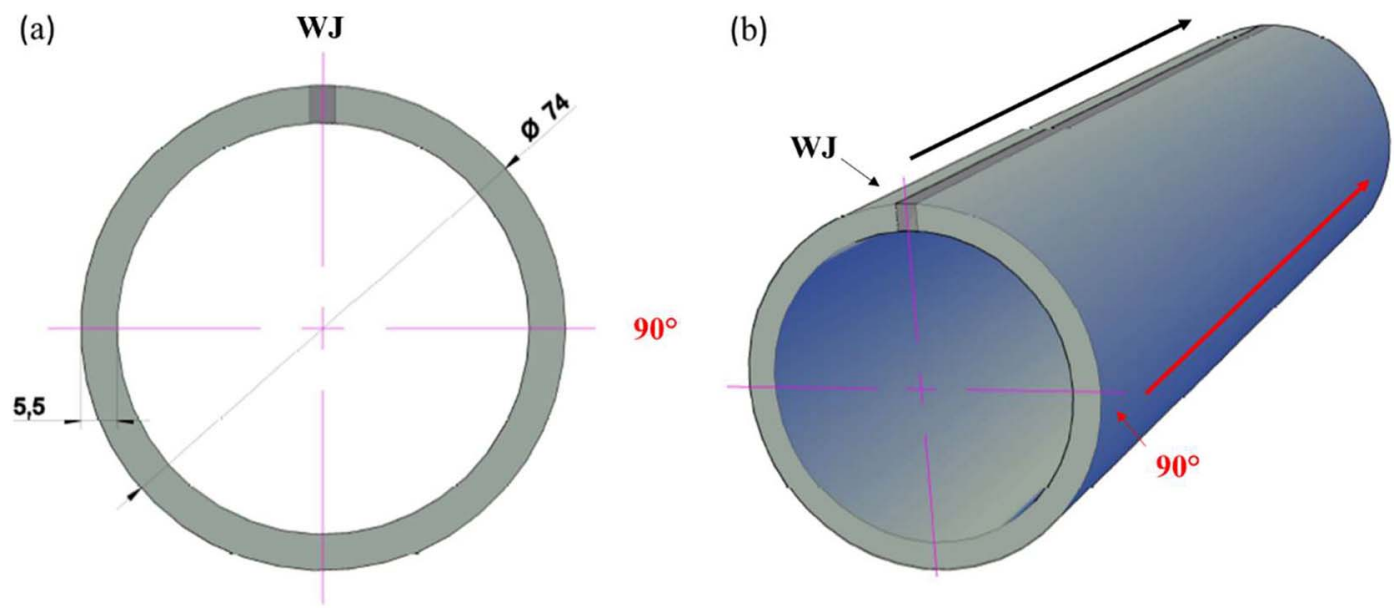

Fig. 1. Steel pipe piece and the two regions of interest WJ and $90^{\circ}$ : (a) front view and (b) in perspective.

changes (e.g. thermal fatigue), complicated "downhole operations" (operations inside oil and gas wells) [5], etc.

It is well known that fatigue cracks will usually nucleate at specific points where stress raisers are present like: geometric discontinuities, small defects (pores, voids, corrosion pits, etc.), inclusions, threads, vicinities of welded joints (which combine both geometric and metallurgical discontinuities) and others. Therefore, to ensure structural integrity and mitigate the effects of fatigue damage, the manufacturing process of the steel pipes, as well their handling and transportation conditions, should be extremely well controlled. The HFIW (High Frequency Induction Welding) process are widely used by the industry in the manufacturing of welded steel pipes [6,7] due advantages like: high productivity, adaptability and no needing of welding consumables [7]. When the HFIW process is followed by austenitization, quenching and temper of the steel tube (like the one studied in this paper), the finished product will usually presents both good mechanical and microstructural homogeneity. However, even after these heat treatments, a subtly weld joint will still be present as well some lack of circularity of the steel tube. In the present work, non-standardized fatigue specimens taken from an API 5CT N80 type Q steel tube (manufactured by HFIW process) have been used to investigate how the welded joint may influence the fatigue resistance of the material, through the analysis of $\mathrm{S}_{\mathrm{a}} \times \mathrm{N}$ curves. Tensile tests, qualitative analysis of the geometry of the welded joint and metallographic analysis have been also done to complement the results obtained.

\section{Material and methods}

\subsection{Steel tubes}

The material used in this research has been provided in the form of a tube, made of a HSLA (High Strength Low Alloy) quenched and tempered steel, manufactured by a HFIW process, as represented in Fig. 1. The chemical composition of the steel is shown in Table 1.

The tube had an outer diameter of $74 \mathrm{~mm}$ and wall thickness equal to $5.5 \mathrm{~mm}$. Initially, the tube, as received, had been divided in two longitudinal directions one aligned with the welded joint (WJ) and other aligned with the $90^{\circ}$ position, as shown in Fig. 1 . After that, it has been cut, with a hydraulic band saw, into smaller pieces (of $300 \mathrm{~mm}$ length each one) before the machining of the tensile and axial fatigue tests specimens.

Table 1

Chemical composition of the steel tube analyzed in this research.

\begin{tabular}{ll}
\hline Chemical element & Percentage by mass [\%] \\
\hline $\mathrm{C}$ & 0.301 \\
$\mathrm{~S}$ & 0.003 \\
$\mathrm{P}$ & 0.028 \\
$\mathrm{Si}$ & 0.25 \\
$\mathrm{Mn}$ & 1.37 \\
$\mathrm{Cr}$ & 0.018 \\
$\mathrm{Ni}$ & $<0.023$ \\
$\mathrm{Mo}$ & 0.0025 \\
$\mathrm{Al}$ & 0.03 \\
$\mathrm{Cu}$ & 0.08 \\
\hline
\end{tabular}




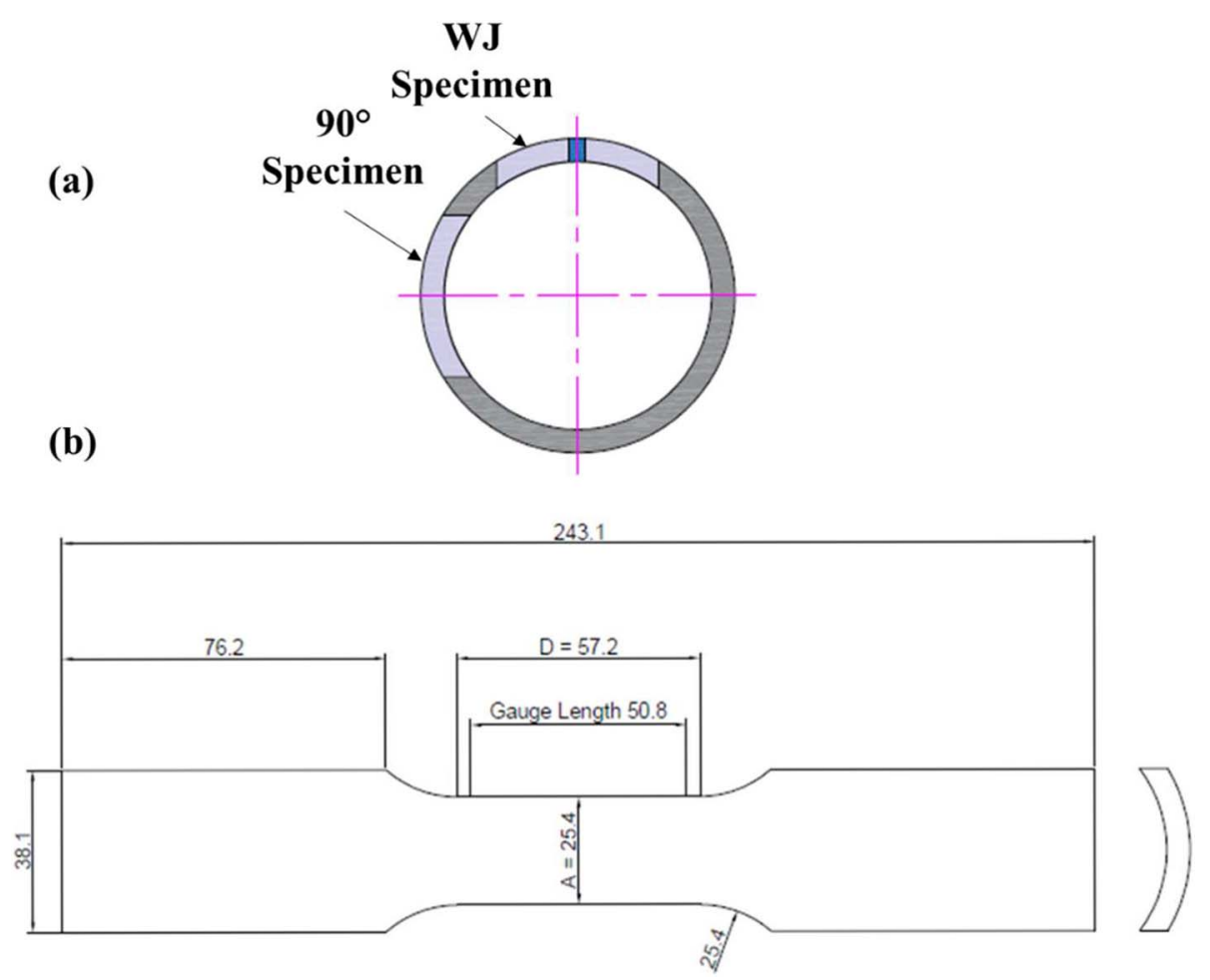

Fig. 2. Steel pipe cross section and respective angular positions used as references in this study: WJ and $90^{\circ}$.

\subsection{Metallography}

Considering both that the HFIW process does not need filler metal and that the tubes are quenched and then tempered it would be expected that both the welded joint and the $90^{\circ}$ position have a similar microstructure and that a HAZ (Heat Affected Zone), if present, should be very subtly. To confirm this, samples taken from the WJ and $90^{\circ}$ positions have been subjected to Nital $5 \%$ etching and optical microscopy analysis.

\subsection{Geometric analysis of the welded joint}

A geometric defect known as lack of circularity (or roundness), may be present in the finished product (due the physical presence of the WJ). To qualitatively evaluate the presence of such defect, images both from the $90^{\circ}$ and WJ positions have been obtained and compared.

\subsection{Tensile tests}

The tensile tests, specimens used in this work had their dimensions in accordance to the standard "ASTM A370 Standard Test Methods and Definitions for Mechanical Testing of Steel Products" and have been machined through EDM (Electrical Discharge Machining). A total of 10 specimens had been machined: 5 aligned with the WJ and 5 aligned with the $90^{\circ}$ position. The dimensions of the tensile test specimens are shown in Fig. 2.

After the preparation of the specimens, the tensile tests have been carried out at room temperature $\left(25^{\circ} \mathrm{C}\right)$ in a Mohr $\&$ Federhaff servo-hydraulic testing machine, with a load cell of $196.2 \mathrm{kN}$, hydraulic grip and a displacement rate of $1.9 \mathrm{~mm} / \mathrm{s}$.

\subsection{Fatigue tests}

The axial fatigue test specimens used in this work also had been taken from the WJ and $90^{\circ}$ positions and were machined by EDM. Although, the fatigue specimens used were round and not flat as the ones proposed by the standard "ASTM E466 Standard Practice for Conducting Force Controlled Constant Amplitude Axial Fatigue Tests of Metallic Materials", which is usually considered as an international reference for axial fatigue testing. A comparison between the geometries of the specimens used in this work and the one proposed by the referred standard is shown in Fig. 3.

It can be noticed that the dimensions of the round and "standardized" specimens are very close: their length, width and radius are the same. These dimensions have been kept in the round specimen to ensure a smooth transition from the grip to the reduced section, avoiding any severe effect of stress concentration. It should be noticed though, that the thickness of the round specimen is equal to the 


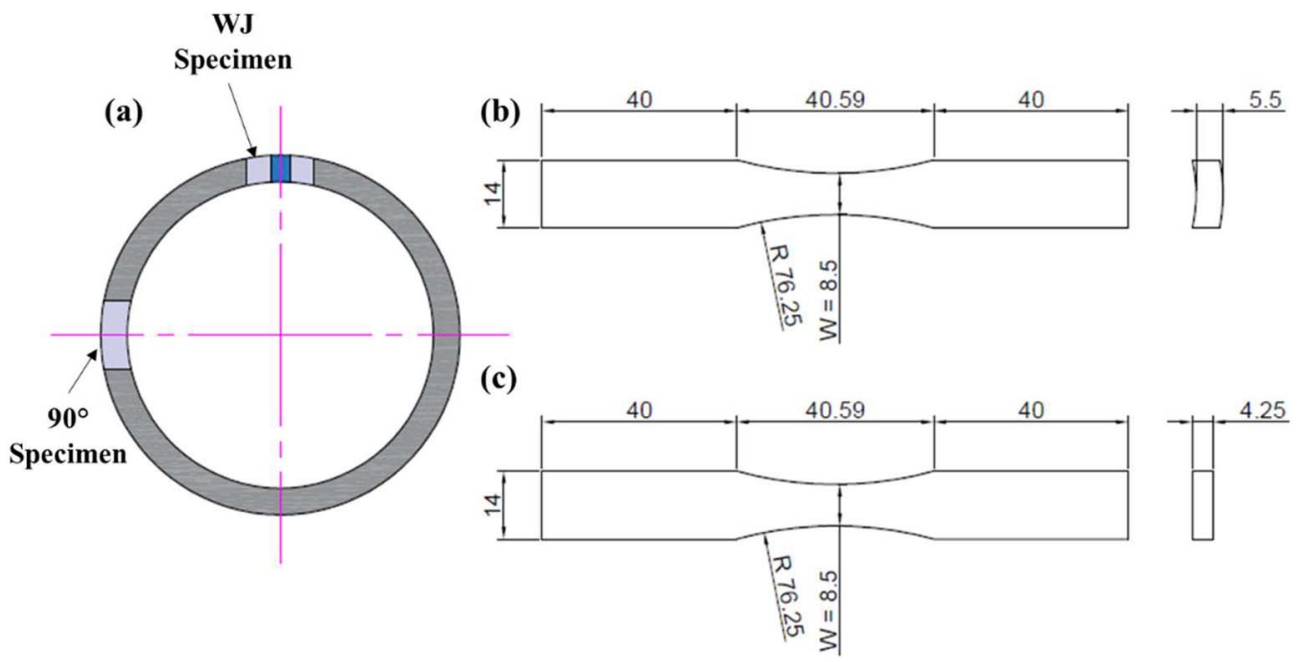

Fig. 3. (a) Positions from where the round axial fatigue specimens had been taken from. (b) Geometry of the round specimen and (c) geometry of the standardized specimen.

tube wall thickness. This fact ensures that the axial fatigue tests are much closer to a real work situation: the cracks can nucleate from defects present in the outer and inner diameter surface of the tube. These defects otherwise could be removed due the extra machining which is needed to ensure a flat geometry of the standardized specimen. Other detail that favors using a round specimen is the fact that the welded joint is kept intact ensuring that its effects as a stress riser can be better evaluated.

After the preparation of 24 specimens ( 11 taken from the WJ and 13 taken from the $90^{\circ}$ position), the axial fatigue tests have been carried out in a servo-hydraulic Instron testing machine (model 8801), with a $100 \mathrm{kN}$ load cell, load ratio (R) of 0.1 , frequency equal to $15 \mathrm{~Hz}$, sinusoidal waveform loading and at room temperature $\left(25^{\circ} \mathrm{C}\right)$. In addition, for each specimen, fatigue strength has been defined as the value of nominal stress amplitude, $\mathrm{S}_{\mathrm{a}}$, at which complete fracture occurs (after "N" cycles) while fatigue limit has been defined as the limiting value of $S_{a}$ at which failure do not occurs after $10^{6}$ cycles (run-out).

\section{Results}

\subsection{Metallurgical analysis}

The results of the metallurgical analysis are shown in Fig. 4. From Fig. 4(b) it can be noticed that there are not a noticeable HAZ (Heat Affected Zone) in the adjacencies of the (very subtly) weld line, and thus it is implied that from a metallurgical point of view the manufactured steel tube should be homogeneous. This is confirmed by Fig. 4(c) and (d). Despite the fact that one image was taken from the WJ and the other from the $90^{\circ}$ position, both exhibit virtually the same tempered/quenched steel microstructure with ferrite (and eventually any retained austenite) in light tones and pearlite, cementite (in the form of small spherical particles) and eventually bainite in darker tones.

\subsection{Qualitative geometric analysis of the welded joint}

The sample used in the qualitative analysis had their $90^{\circ}$ and $\mathrm{WJ}$ positions identified as shown in Fig. 5. After this, frontal views images of both positions have been obtained through microscopy and then adjusted, with the software ImageJ, as presented in Fig. 6 . From Fig. 6 it can be noticed, qualitatively, that the WJ position has much less circular geometry when it is compared to the $90^{\circ}$ position. In particular, when both external perimeters are compared, it is clear that the WJ has a much "flatter" geometry. The presence of such defect may be detrimental to the tube structural integrity, potentially reducing its resistance to fatigue as well to plastic collapse.

\subsection{Tensile tests}

The results of the tensile tests are presented in Table 2 .

According to these results and considering $\alpha$ (significance level) $=5 \%$, there is no statistical evidence that the values of $\sigma_{\text {yield } 0.5 \%}$, $\sigma_{\mathrm{u}}, \sigma_{\text {rup }}$ and $\delta$ for the WJ and $90^{\circ}$ positions are different. Therefore, the steel tube is, apparently, not only metallurgical homogeneous, but mechanical homogeneous as well. 

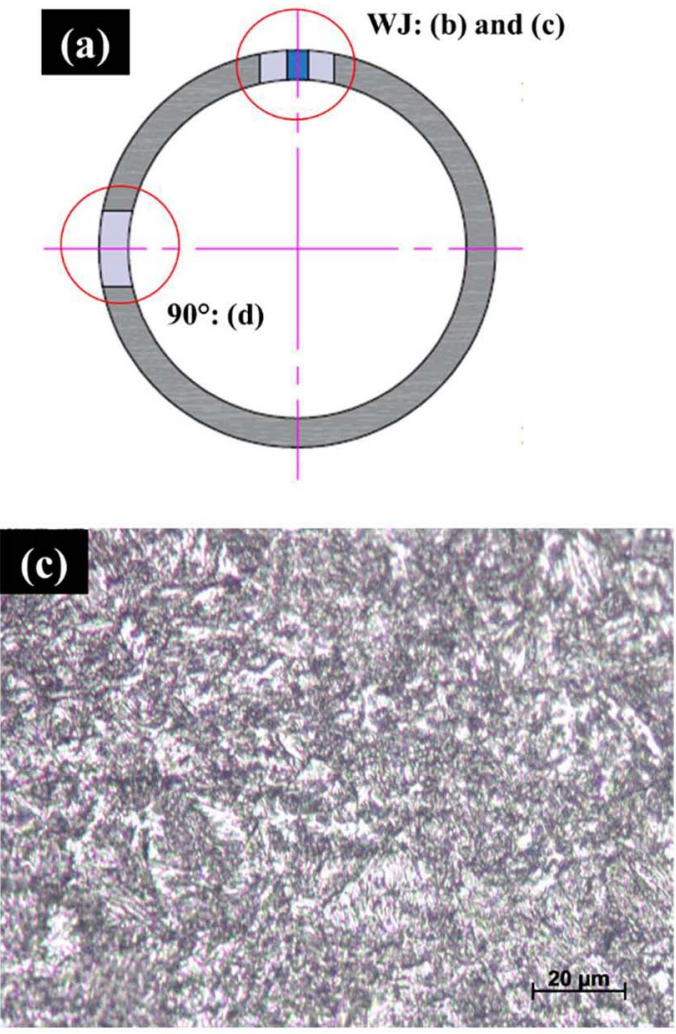
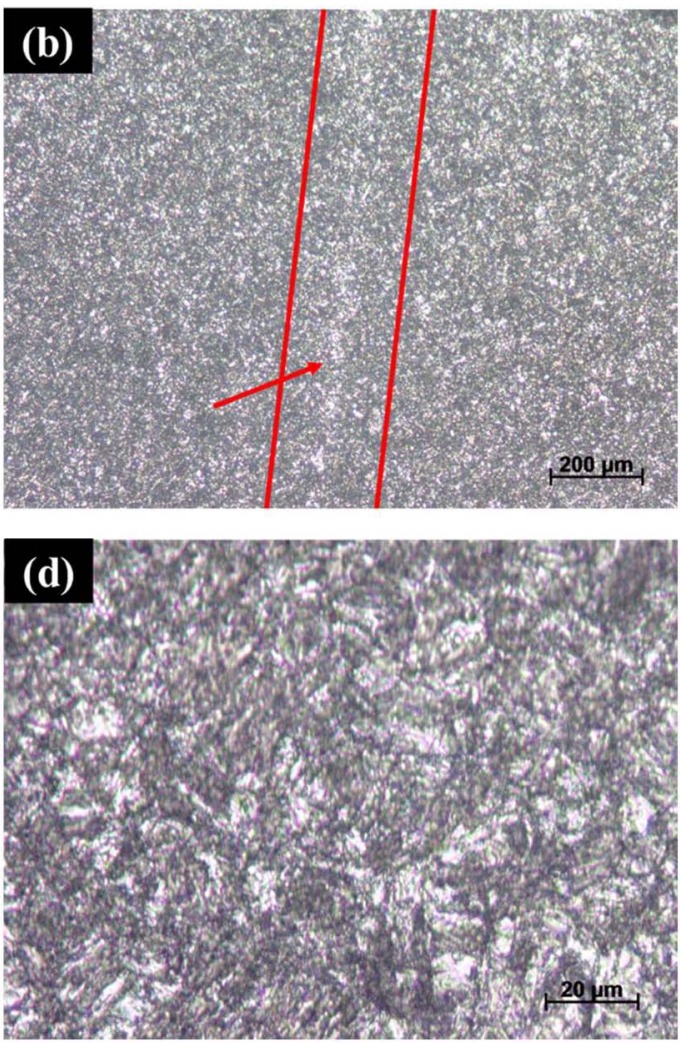

Fig. 4. (a) Reference positions; (b) subtly WJ line indicated by the red arrow; images with higher magnification, showing a typical quenched/tempered steel microstructure for the $90^{\circ}$ position in (c) and the WJ in (d). (For interpretation of the references to colour in this figure legend, the reader is referred to the web version of this article.)

\subsection{Fatigue tests}

Fig. 7 presents the complete $\mathrm{S}_{\mathrm{a}}-\mathrm{N}$ curve for the axial fatigue tests, both from $\mathrm{WJ}$ and $90^{\circ}$ position specimens, with the results being detailed in Tables 3 and 4 .

To compare the fatigue resistance of the specimens aligned with the $\mathrm{WJ}$ and $90^{\circ}$ position, linear regressions have been made with statistical analysis of the results in accordance to the methodology proposed in the standard "ASTM E739 Statistical Analysis of Linear

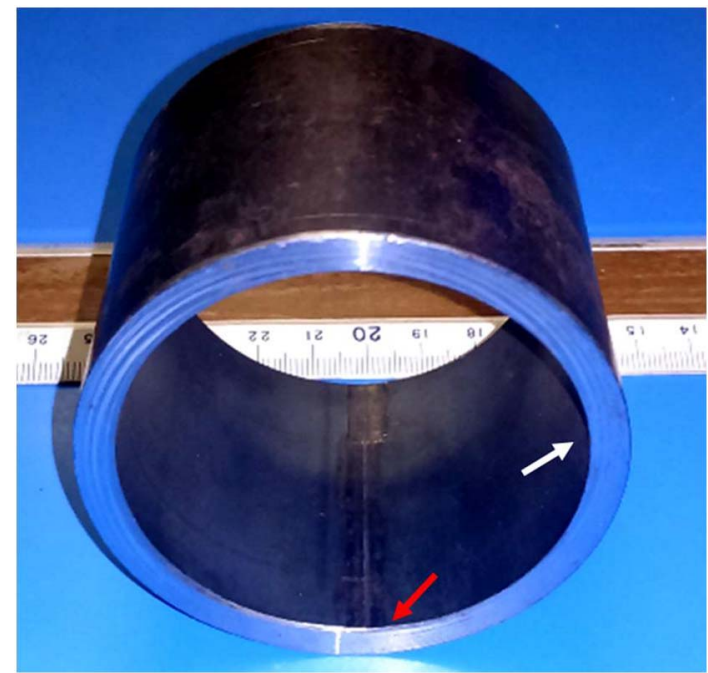

Fig. 5. Steel tube sample with $90^{\circ}$ and $\mathrm{WJ}$ position being identified by the white arrow and red arrow respectively. (For interpretation of the references to colour in this figure legend, the reader is referred to the web version of this article.) 


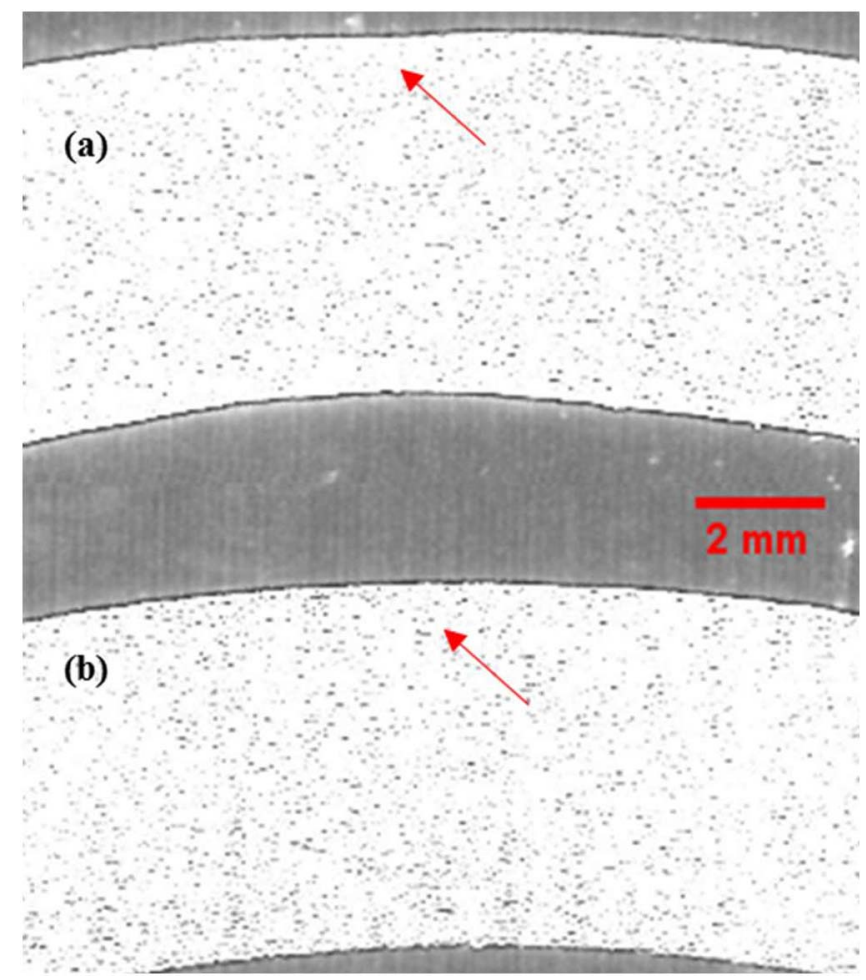

Fig. 6. Closer view of (a) the WJ and (b) the $90^{\circ}$ position. From a qualitative analysis, it can be noticed that the WJ has a less "circular" external perimeter when compared to the $90^{\circ}$ position, as indicated by the red arrows. (For interpretation of the references to colour in this figure legend, the reader is referred to the web version of this article.)

or Linearized Stress Life (S-N) and Strain-Life $(\varepsilon-\mathrm{N})$ Fatigue Data". The results of these linear regressions are shown in the form of functions $\mathrm{N}=f\left(\mathrm{~S}_{\mathrm{a}}\right)$, both for the $90^{\circ}$ and $\mathrm{WJ}$ positions:

$$
\begin{aligned}
& \mathrm{N}_{90} \circ\left(\mathrm{S}_{\mathrm{a}}\right)=10^{25.67} \cdot \mathrm{S}_{\mathrm{a}}^{-8.33} \\
& \mathrm{~N}_{\mathrm{WJ}}\left(\mathrm{S}_{\mathrm{a}}\right)=10^{11.75} \cdot \mathrm{S}_{\mathrm{a}}^{-2.65}
\end{aligned}
$$

with the units of $\mathrm{N}$ and $\mathrm{S}_{\mathrm{a}}$ being cycles and MPa respectively. Both Eqs. (1) and (2) represent straight lines in a log-log scale and are graphically represented in Figs. 8 and 9 along a 95\% CI (Confidence Interval), a 95\% PI (Predict Interval) and the experimental points, which have been used in the linear regressions.

\section{Discussion}

From Fig. 7 and Tables 2, 3 and 4, one can observe that this API 5CT N80 type Q steel presents, for these test conditions, values of fatigue limit of around $30 \%$ of the steel ultimate tensile strength. Some of the $90^{\circ}$ position specimens have achieved the "run-out" for values of $S_{a}=248[\mathrm{MPa}]$, while the WJ specimens only achieved the "run-out" for values of $S_{a}=225[\mathrm{MPa}$.

Table 2

\begin{tabular}{|c|c|c|c|c|}
\hline & $\sigma_{\text {yield } 0.5 \%[\mathrm{MPa}]}$ & $\sigma_{\mathrm{u}}[\mathrm{MPa}]$ & $\sigma_{\text {rup }}[\mathrm{MPa}]$ & $\delta[\mathrm{mm} / \mathrm{mm}]$ \\
\hline \multicolumn{5}{|l|}{ Welded joint } \\
\hline Mean & 489.70 & 830.70 & 691.00 & 0.21 \\
\hline Standard deviation & 55.80 & 41.30 & 3.80 & 0.01 \\
\hline Lower bound $(\alpha=5 \%)$ & 420.43 & 799.43 & 686.28 & 0.20 \\
\hline Upper bound $(\alpha=5 \%)$ & 558.97 & 881.97 & 695.72 & 0.22 \\
\hline \multicolumn{5}{|l|}{$90^{\circ}$ position } \\
\hline Mean & 496.80 & 871.50 & 767.50 & 0.21 \\
\hline Standard deviation & 37.70 & 9.80 & 93.20 & 0.01 \\
\hline Lower bound $(\alpha=5 \%)$ & 450.00 & 859.33 & 651.80 & 0.20 \\
\hline Upper bound $(\alpha=5 \%)$ & 543.60 & 883.67 & 883.20 & 0.22 \\
\hline
\end{tabular}

Tensile test results. 


\section{$S_{a} \times N$ curve for $90^{\circ}$ and $W J$ positions}

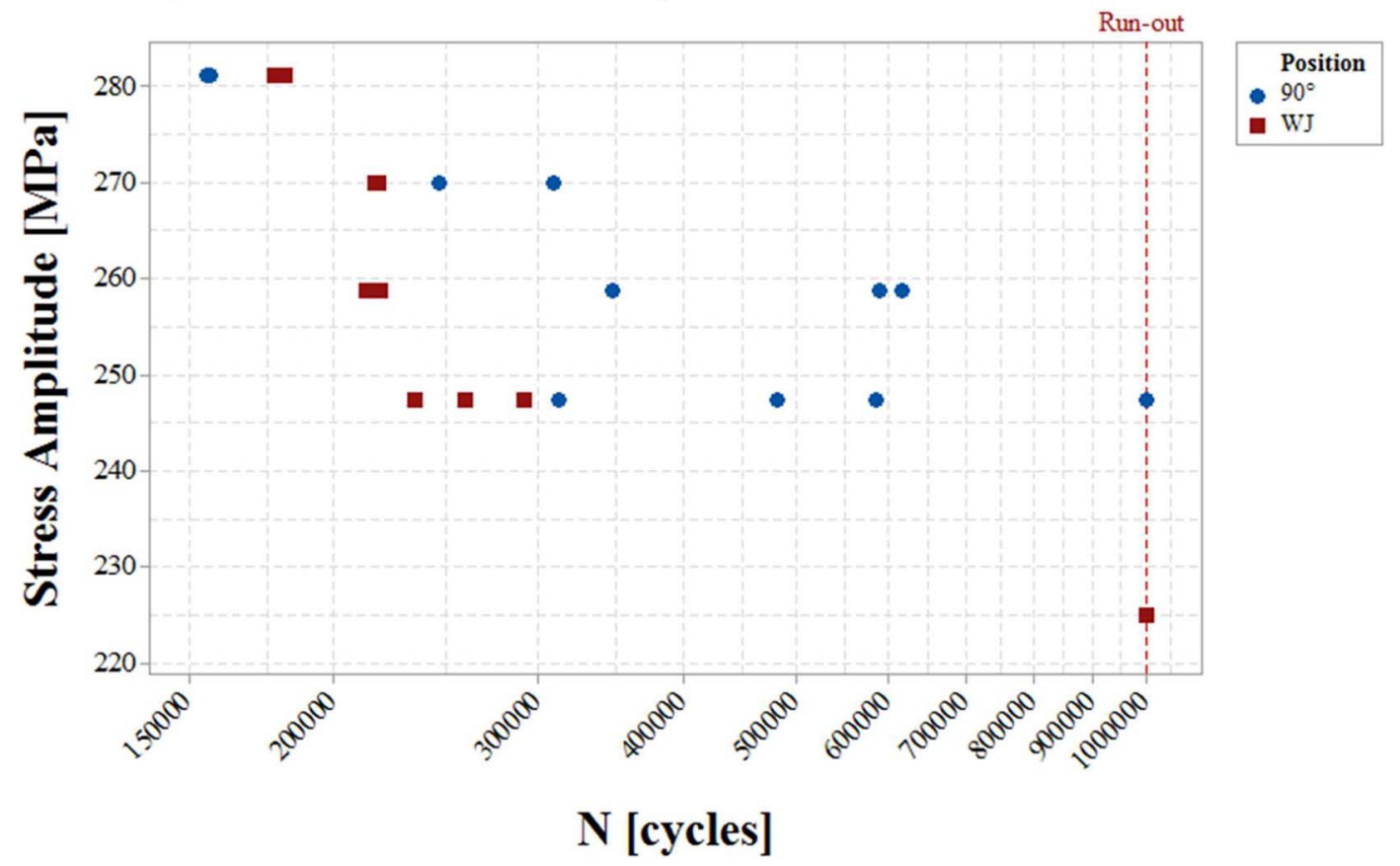

Fig. 7. $\mathrm{S}_{\mathrm{a}}-\mathrm{N}$ curve showing the results obtained in the axial fatigue tests for both positions: $90^{\circ}$ and WJ.

Concerning the dispersion of the fatigue resistance values for each stress level, it can be noticed that dispersion has increased with the increment of $S_{a}$ (which is normally expected in fatigue tests). In addition, the dispersion has been, in average, higher for the $90^{\circ}$ position. This may indicate that the presence of the WJ facilitates the nucleation of fatigue cracks in its adjacencies from some preferential defects, while in the $90^{\circ}$ position the cracks may nucleate from a larger array of superficial defects (explaining the higher dispersion of $\mathrm{N}$ values).

Despite the fact that there are not significant mechanical (according to the tensile tests) or significant metallurgical differences between the two positions analyzed, through the analysis of Figs. 8 and 9 it can be noticed that the specimens taken from the $90^{\circ}$ position have, in average, higher values of fatigue resistance than the ones observed for the WJ position. In addition, as presented in Fig. 6, there is a noticeable geometric discontinuity in the adjacencies of the WJ. Therefore, from the analysis of the fatigue test results it can be hypothesized that the HFIW welded joint, due its more "irregular" geometry, may act as a notch, decreasing the fatigue resistance of the steel tube. It should be stressed that the presence of this defect may be related both to the HFIW process itself as well the subsequent longitudinal grinding of the WJ.

For a given material, the macroscopy presence of a notch (or any other similar stress riser) can effectively reduce the material fatigue resistance. For a given notch geometry (notch radius) and a specific material, this effect in fatigue can be predicted by the following equation:

Table 3

Fatigue test results $\left(90^{\circ}\right.$ position).

\begin{tabular}{lll}
\hline Fatigue test results $-90^{\circ}$ position & & \\
\hline Specimen & $\mathrm{S}_{\mathrm{a}}[\mathrm{MPa}]$ & N [cycles] \\
\hline 1 & 225 & $1,000,000$ \\
2 & 248 & $1,000,000$ \\
3 & 248 & $1,000,000$ \\
4 & 248 & 586,871 \\
5 & 248 & 482,078 \\
6 & 248 & 311,875 \\
7 & 259 & 617,901 \\
8 & 259 & 589,097 \\
9 & 259 & 347,184 \\
10 & 270 & 309,668 \\
11 & 270 & 246,179 \\
12 & 281 & 156,623 \\
13 & 281 & 155,241 \\
\end{tabular}


Table 4

Fatigue test results (WJ position).

\begin{tabular}{|c|c|c|}
\hline \multicolumn{3}{|c|}{ Fatigue test results $-\mathrm{WJ}$ position } \\
\hline Specimen & $\mathrm{S}_{\mathrm{a}}[\mathrm{MPa}]$ & $\mathrm{N}$ [cycles] \\
\hline 1 & 225 & $1,000,000$ \\
\hline 2 & 225 & $1,000,000$ \\
\hline 3 & 248 & 291,920 \\
\hline 4 & 248 & 259,142 \\
\hline 5 & 248 & 234,565 \\
\hline 6 & 259 & 219,494 \\
\hline 7 & 259 & 213,182 \\
\hline 8 & 270 & 218,215 \\
\hline 9 & 270 & 217,349 \\
\hline 10 & 281 & 181,458 \\
\hline 11 & 281 & 177,973 \\
\hline
\end{tabular}

$$
\mathrm{K}_{\mathrm{f}}=1+\mathrm{q} \bullet\left(\mathrm{K}_{\mathrm{t}}-1\right)
$$

being "q" the material's notch sensitivity (function of the notch radius and material properties [8]), $\mathrm{K}_{\mathrm{t}}$ the theoretical stress concentration factor (function of the notch geometry and valid for elastic stresses [9]) and $\mathrm{K}_{\mathrm{f}}$ the fatigue stress concentration factor.

Eq. (3) is more suitable for values of $S_{a}=$ "fatigue limit", i.e. the value of $K_{f}$ may be too conservative if lower values of $S_{a}$ are being applied. This happens because the value of $K_{f}$ changes with the increment or decrement of the applied $S_{a}$ (nominal stress amplitude). As $S_{a}$ increases, the effects of plasticity at the notch's root also increase, leading to a "relief" of the stress concentration effect, i.e. there is a drop in the value of $K_{f}$ and the stress riser effect of the notch is reduced. In addition, it should be noticed that, as $\mathrm{S}_{\mathrm{a}}$ increases, $\mathrm{K}_{\mathrm{f}}$ converges to a minimum value of 1 . When $\mathrm{S}_{\mathrm{a}}$ decreases, the opposite happens: the effect of plasticity decreases and, in this case, $\mathrm{K}_{\mathrm{f}}$ increases and approaches to the theoretical value $\mathrm{K}_{\mathrm{t}}$.

It might not be easy to find appropriate values of $\mathrm{q}$ for a specific notch geometry or material. This is especially important in the analysis of welded elements. A welded joint may have an irregular geometry and locally impact the material mechanical properties (due microstructural changes in the HAZ). Thus, more commonly, for a given number of cycles $\mathrm{N}^{*}, \mathrm{~K}_{\mathrm{f}}$ is obtained from " $\mathrm{S}_{\mathrm{a}} \times \mathrm{N}$ " curves for specific points through the following relationship:

$$
\mathrm{K}_{\mathrm{f}}=\frac{\text { Fatigue resistance (notched element) for } \mathrm{N}^{*} \text { cycles }}{\text { Fatigue resistance (unotched element) for } \mathrm{N}^{*} \text { cycles }}
$$

\section{Linear Regression for the $90^{\circ}$ position}

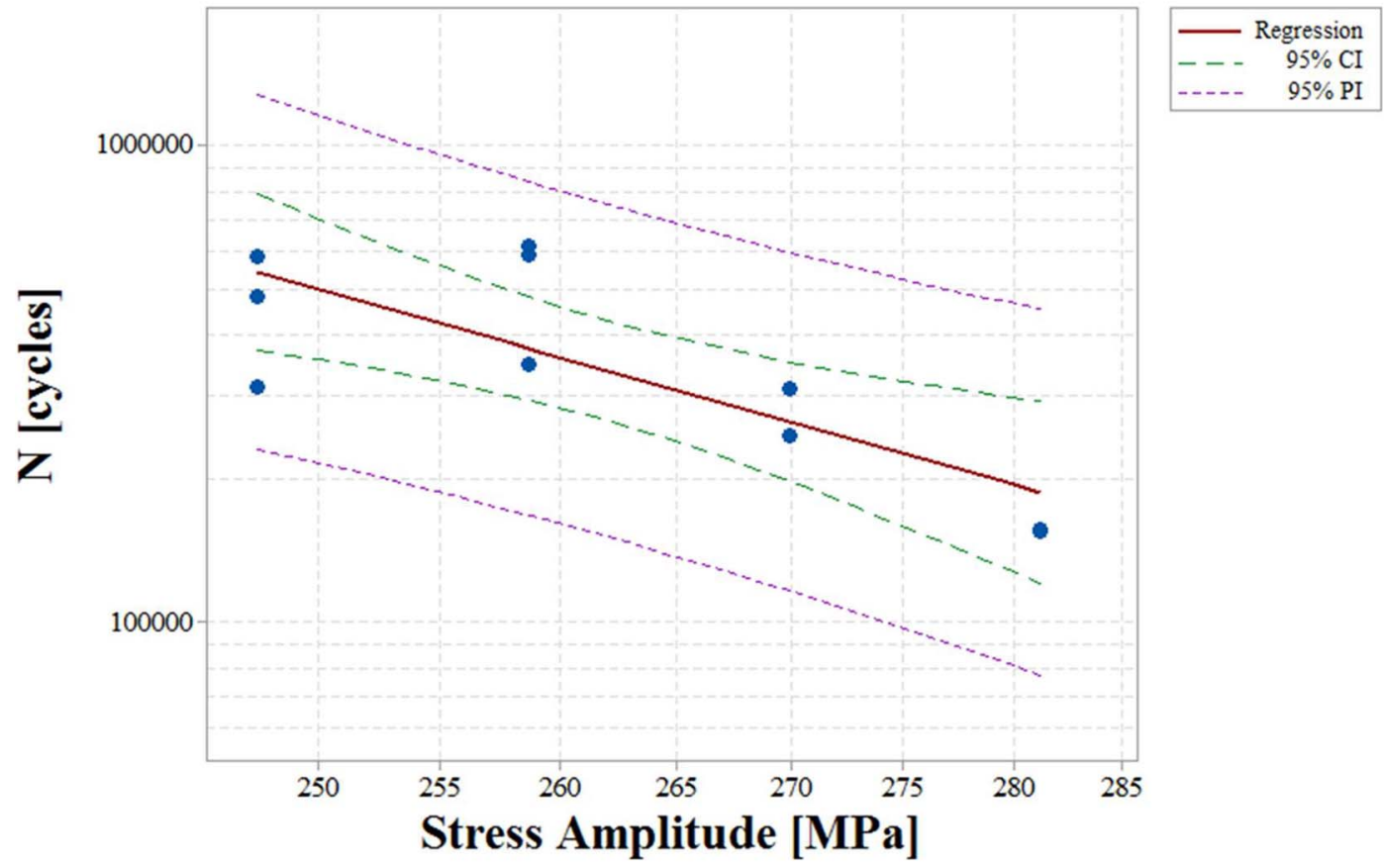

Fig. 8. $90^{\circ}$ position specimens: experimental points and respective linear regression, 95\% CI and 95\% PI. 


\section{Linear Regression for the WJ position}

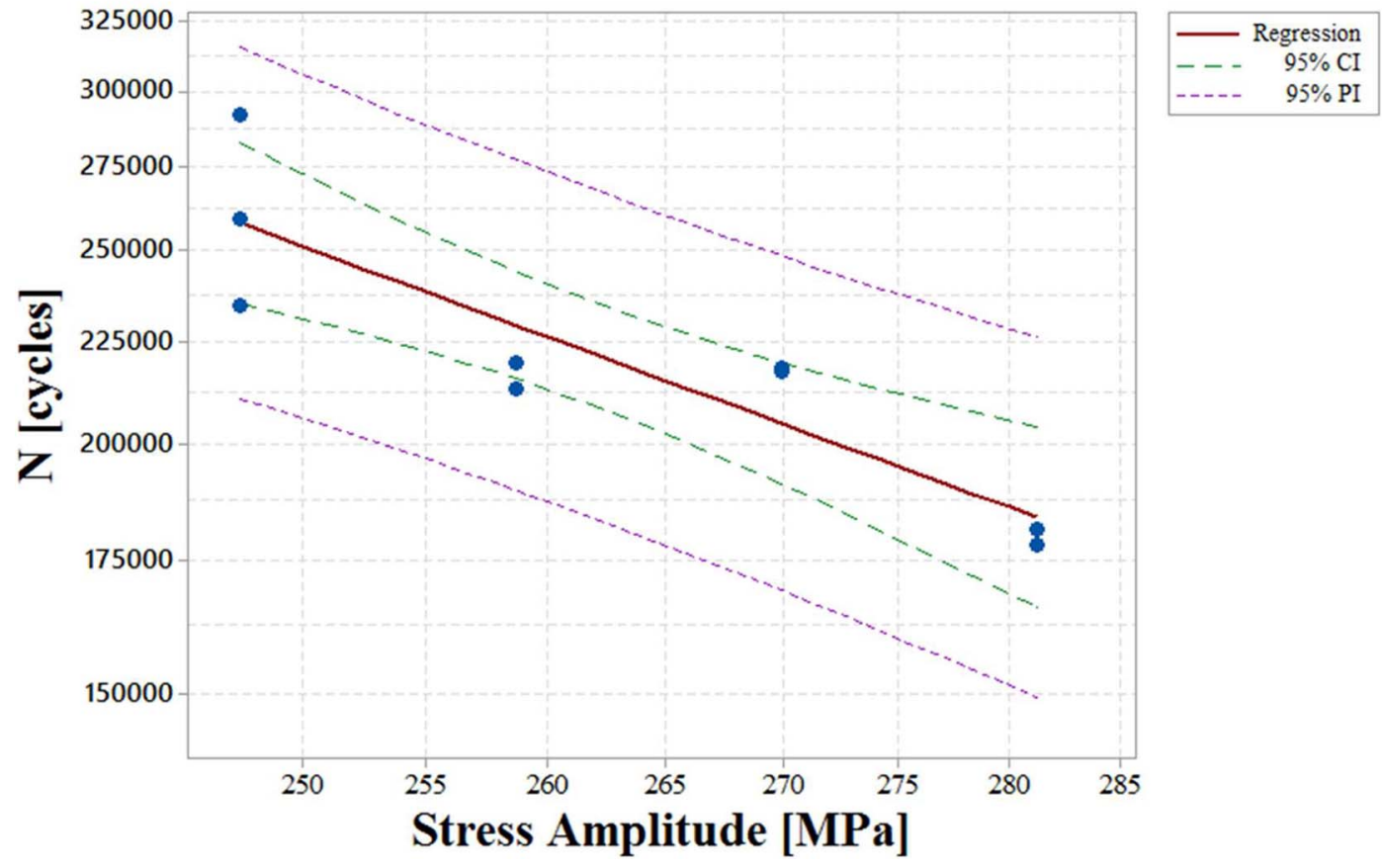

Fig. 9. WJ position specimens: experimental points and respective linear regression, 95\% CI and 95\% PI.

Considering both that the number of cycles, $\mathrm{N}$, is the response to the applied stress amplitude, $\mathrm{S}_{\mathrm{a}}$ (predictor), and that $\mathrm{K}_{\mathrm{f}}$ changes with $S_{a}$, the authors propose that it may be useful estimate a function $K_{f^{\prime} \text {-notch }}=f\left(S_{a}\right)=\eta \cdot S_{a}{ }^{\gamma}$ and evaluate its behavior. Then, from Eqs. (1) and (2):

$$
\begin{aligned}
& \mathrm{K}_{\mathrm{f}^{\prime}-\operatorname{notch}}\left(\mathrm{S}_{\mathrm{a}}\right)=f\left(\mathrm{~S}_{\mathrm{a}}\right)=\eta \cdot \mathrm{S}_{\mathrm{a}}^{\gamma} \\
& \mathrm{K}_{\mathrm{f}^{\prime}}\left(\mathrm{S}_{\mathrm{a}}\right)=f\left(\mathrm{~S}_{\mathrm{a}}\right)=\mathrm{N}_{90}{ }^{\circ}\left(\mathrm{S}_{\mathrm{a}}\right) / \mathrm{N}_{\mathrm{WJ}}\left(\mathrm{S}_{\mathrm{a}}\right) \\
& \mathrm{K}_{\mathrm{f}^{\prime}-\mathrm{WJ}}\left(\mathrm{S}_{\mathrm{a}}\right)=10^{13.92} \cdot \mathrm{S}_{\mathrm{a}}^{-5.68}
\end{aligned}
$$

being $\mathrm{K}_{\mathrm{f}^{\prime}-\mathrm{WJ}}$ dimensionless and $\mathrm{S}_{\mathrm{a}}$ given in MPa.

The parameters $\eta$ and $\gamma$, proposed in Eq. (4), are functions of the average geometry of the notch and material properties. Therefore, they might be used to evaluate how the manufacturing processes and their variations impact on the fatigue resistance of a given element. For instance, a steel tube manufacturer may be interested in how a new grinding process of the WJ may affect the fatigue resistance of the tube. In this case, the manufacturer could change the process, measure new values of $\eta$ and $\gamma$ (through fatigue tests), compare these new values with the ones that he has as a reference and, finally, evaluate if the process change was beneficial, detrimental or neutral concerning the fatigue properties of the finished product. Nevertheless, despite the fact that this work is focused in the study of steel tubes used in the oil and gas industry, the procedure which had been described can also be used by other industries which are concerned with the fatigue resistance of their finished products.

Using the proposed model $\mathrm{K}_{\mathrm{f}^{\prime} \text {-notch }}=f\left(\mathrm{~S}_{\mathrm{a}}\right)$, it is possible to estimate, using Eq. (6), that for $\mathrm{S}_{\mathrm{a}} \approx 282.3$ [MPa], $\mathrm{K}_{\mathrm{f}^{\prime} \text {-WJ }} \approx 1.0$. From this analysis, it is possible to infer that the specimens are insensitive to the WJ presence for values of $S_{a} \geq 282.3$ [MPa]. However, for these cases, Eq. (6) provides values that are lower than 1.0, which do not have a correct physical sense (the presence of the notch would increase the specimen resistance to fatigue). Therefore, when using the $\mathrm{K}_{\mathrm{f}^{\prime}-\mathrm{WJ}}$ model, some attention must be paid to the function domain. It is worth noticing also, that Eq. (6) have been obtained from Eqs. (1) and (2), which, in accordance to the statistical analysis developed, do not consider data from censored tests ("run-outs"). Therefore, it is convenient to apply Eq. (6) only for values equal or higher than 248 [MPa], which had been used in the linear regressions calculation. In resume:

$$
\left\{\begin{array}{l}
\text { being } \mathrm{S}_{\mathrm{a}} \geq 248 \mathrm{MPa} \\
\text { if } \mathrm{S}_{\mathrm{a}}:[248 ; 282.3[ \\
\mathrm{K}_{\mathrm{f}^{\prime}-\mathrm{WJ}}\left(\mathrm{S}_{\mathrm{a}}\right)=10^{13.92} \cdot \mathrm{S}_{\mathrm{a}}^{-5.68} \\
\text { if } \mathrm{S}_{\mathrm{a}} \geq 282.3[\mathrm{MPa}] \\
\mathrm{K}_{\mathrm{f}^{\prime}-\mathrm{WJ}}=1.0
\end{array}\right.
$$

In accordance to the proposed model, the values of $\mathrm{K}_{\mathbf{f}^{\prime}-\mathrm{WJ}}$ are graphically represented in Fig. 10. From Fig. 10, it is possible to 


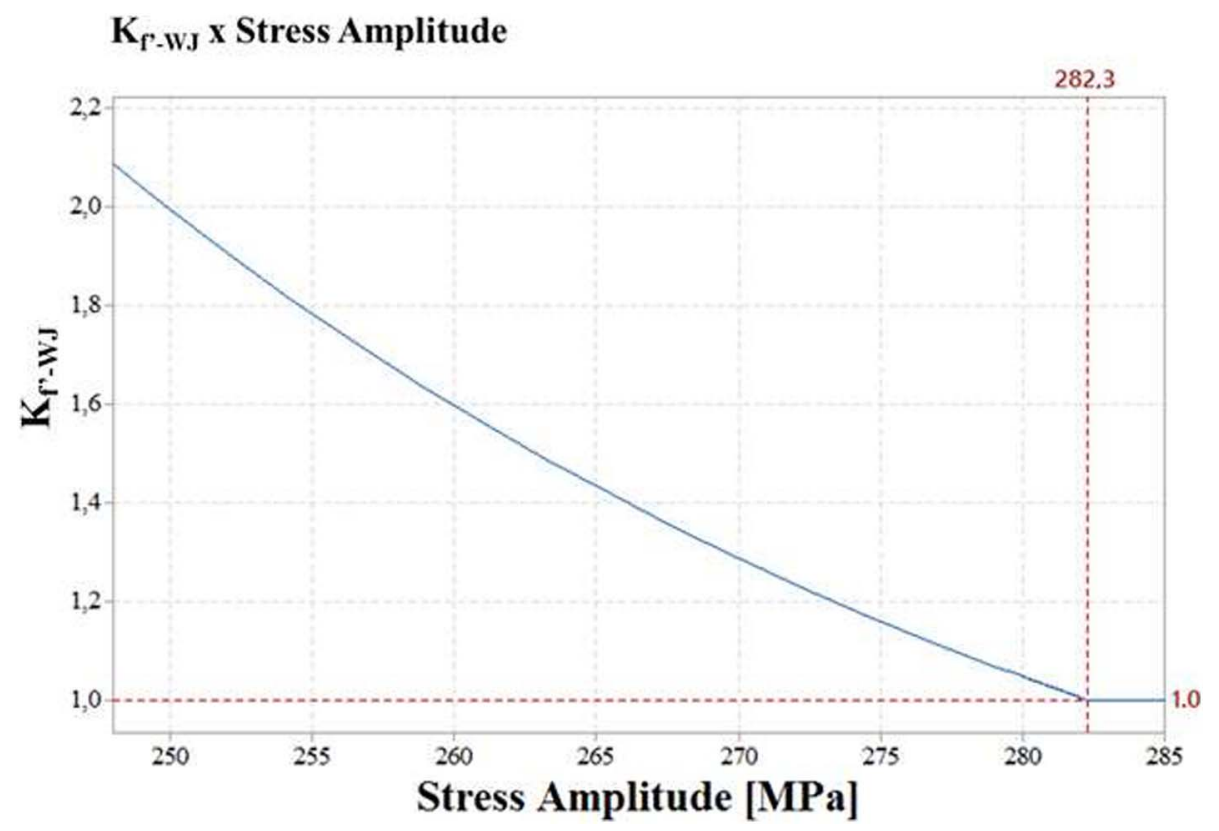

Fig. 10. $\mathrm{K}_{\mathrm{f}^{\prime}-\mathrm{WJ}} \times \mathrm{S}_{\mathrm{a}}$ curve, valid for $\mathrm{S}_{\mathrm{a}}$ equal or higher than $248\left[\mathrm{MPa}\right.$ ]. For values of $\mathrm{S}_{\mathrm{a}}$ higher than 282.3 [MPa] the specimens are insensitive to the WJ presence.

notice that the values of $\mathrm{K}_{\mathrm{f}^{\prime}-\mathrm{WJ}}$ decreases as $\mathrm{S}_{\mathrm{a}}$ increases, corroborating the hypothesis that the WJ acts as a stress concentrator.

\section{Conclusion}

In this research a study to evaluate the fatigue resistance of an API 5CT N80 type Q steel tube has been made. From the results obtained, it is possible to conclude that the quenched/tempered steel tube manufactured by HFIW process has good metallurgical homogeneity and mechanical isotropy (according to the tensile tests). However, despite these facts, the fatigue resistance of specimens aligned with the $90^{\circ}$ position was, in average, higher than the resistance of specimens aligned with the welded joint. This indicates that the welded joint of the tube, which had been kept intact due the use of non-standardized specimens, being a geometric discontinuity, acts as notch, a stress concentrator and clearly decreases the tubes resistance to fatigue, hypothesis that has been corroborated by the analysis of $\mathrm{K}_{\mathrm{f}^{\prime}-\mathrm{WJ}}$. Finally, the authors propose that, for a given notched element, it might be useful to estimate functions in the form of $\mathrm{K}_{\mathrm{f}^{\prime} \text {-notch }}=f\left(\mathrm{~S}_{\mathrm{a}}\right)=\eta \cdot \mathrm{S}_{\mathrm{a}}{ }^{\gamma}$. Through them (and using a valid $\mathrm{S}_{\mathrm{a}}$ value), it is possible to directly estimate the impact of a given notch in the fatigue resistance of a mechanical element or specimen. In addition, it is possible also to use the parameters $\eta$ and $\gamma$ to evaluate how and if changings in the manufacturing processes impact in the fatigue resistance of the finished product.

\section{References}

[1] M.A. Al-Anezi, S. Rao, G.R. Lobley, Pipeline failure by transite fatigue, J. Fail. Anal. Prev. 9 (2009) 35-38.

[2] S. Papavinasam, Corrosion Control in the Oil and Gas Industry, first ed., Wyman Street, Waltham, 2014.

[3] J. Wang, S. Fu, Fatigue damage induced by vortex-induced vibrations in oscillatory flow, Mar. Struct. 40 (2015) $73-91$.

[4] Y. Bai, Q. Bai, Subsea Pipelines and Risers, first ed., Langford Lane Kidlington, Oxford, 2005.

[5] W. Renpu, Advanced Well Completion Engineering, third ed., Wyman Street, Waltham, 2011.

[6] I.J. Santana, P. Balsamo, P.J. Modenesi, High frequency induction welding simulating on ferritic stainless steels, J. Mater. Process. Technol. 179 (2006) 225-230.

[7] P. Yan, Ö.E. Güngor, P. Thibaux, M. Liebeherr, H.K.D.H. Bhadeshia, Tackling the toughness of steel pipes produced by high frequency induction welding and heattreatment, Mater. Sci. Eng. A 528 (2011) 8492-8499.

[8] W.D. Pilkey, Peterson's Stress Concentration Factors, second ed., Third Avenue, New York, 1997.

[9] C.P.M. Pereira, Mecânica dos Materiais Avançada, first ed., Rua Verna Magalhães, Rio de Janeiro, 2014. 